\title{
Desempenho e atividades enzimáticas em girinos de rã-touro
}

\author{
José Teixeira de Seixas Filho(1), Maria Goreti Almeida Oliveira( ${ }^{(2)}$, Guilherme de Souza Moura ${ }^{(3)}$, \\ Silvana Lages Ribeiro Garcia ${ }^{(4)}$, Eduardo Teixeira Arruda Lanna( ${ }^{(3)}$ e Lilia Nogueira da Silva ${ }^{(1)}$
}

\begin{abstract}
(1)Centro Universitário Augusto Motta, Laboratório de Pesquisa em Biologia, Avenida Paris, № 72, Bonsucesso, CEP 21041-020 Rio de Janeiro, RJ. E-mail: seixasfilho@unisuam.edu.br, lilinog6@yahoo.com.br (2)Universidade Federal de Viçosa (UFV), Departamento de Bioquímica e Biologia Molecular, Avenida P.H. Rolfs, s/no, Campus Universitário, CEP 36570-000 Viçosa, MG. E-mail: malmeida@ufv.br ${ }^{(3)}$ UFV, Departamento de Zootecnia. E-mail: mouraguilherme@yahoo.com.br, elanna@ufv.br ${ }^{(4)}$ Faculdade de Viçosa, Rua Dr. Milton Bandeira, no 380, CEP 36570-000 Viçosa, MG. E-mail: garciasılr@yahoo.com.br
\end{abstract}

Resumo - O objetivo deste trabalho foi avaliar o desempenho e as atividades das enzimas digestivas de girinos de rã-touro, alimentados com ração comercial durante 60 dias, com um girino por litro, em caixas com $30 \mathrm{~L}$ de água. Os parâmetros medidos quinzenalmente foram: sobrevivência, comprimento, peso final, consumo de ração, e a atividade de amilase, lipase e tripsina. O maior crescimento dos girinos foi do 150 ao 45 o dia $-20,61 \mathrm{~mm}$. Durante os primeiros 15 dias, os girinos apresentaram a maior taxa de crescimento específico, $16,73 \%$ por dia. Do $45^{\circ}$ ao $60^{\circ}$ dia, os girinos apresentaram o maior ganho de peso, $3,98 \pm 0,73 \mathrm{~g}$, o maior consumo de ração, $14,40 \pm 1,14 \mathrm{~g}$, e a melhor conversão alimentar, 3,67:1,0 0,18 . Houve aumento significativo da atividade enzimática depois do $30^{\circ}$ dia. Observaram-se relações entre as atividades específicas das enzimas e os distintos estágios de desenvolvimento dos girinos.

Termos para indexação: Lithobathes catesbeianus, enzimologia, girinagem, morfofisiologia, nutrição animal, ranicultura.

\section{Performance and enzymatic activities of the bullfrog tadpoles}

\begin{abstract}
The objective of this study was to evaluate the performance and the digestive enzyme activity in bullfrog tadpoles, fed with commercial ration during 60 days, at the density of one tadpole per liter in 30 L boxes. The parameters measured fortnightly were: survival, length, weight, ration consumption, and amylase, lipase and trypsin activities. There larger growth of the tadpoles occurred from the $15^{\text {th }}$ to the $45^{\text {th }}$ day $-20.61 \mathrm{~mm}$. During the first 15 days, the tadpoles had the largest specific growth rate, $16.7 \%$ per day. From the $45^{\text {th }}$ to the $60^{\text {th }}$ day, the tadpoles had the largest weight gain, $3.98 \pm 0.73 \mathrm{~g}$, the largest ration consumption, $14.40 \pm 1.14 \mathrm{~g}$ and the best feed conversion, 3.67:1.0 0.18 . There was significant increase in enzyme activities after the $30^{\text {th }}$ day. Relationships were observed between the specific enzyme activities and the different development phases of the tadpoles.
\end{abstract}

Index terms: Lithobathes catesbeianus, enzymology, bullfrog farming, morphophysiology, animal nutrition, tadpole production.

\section{Introdução}

A fase de girinagem constitui a base da ranicultura, uma vez que contribui decisivamente para o sucesso da produção de imagos sadios e de bom peso, ou para o insucesso da criação, resultando em mortalidade ou morbidade de animais, ocasionadas por procedimentos zootécnicos executados de forma empírica, principalmente a administração de alimentos inadequados, uma vez que pouco se conhece sobre as exigências nutricionais das rãs, as quais proporcionariam melhores desempenhos aos animais (Seixas-Filho, 1998a,1998b).

A nutrição de rãs teve como principal conquista, na década de 1980, a aceitação de ração pelos animais. Entretanto, existe a necessidade de estudos a fim de se obter dietas econômica e biologicamente adequadas, pois alguns níveis de nutrientes ainda são inferidos a partir das exigências de outros animais, principalmente peixes (Lima \& Agostinho, 1992).

As relações entre o regime alimentar e as características do aparelho digestório vêm sendo 
estudadas em outros grupos zoológicos, em que a tecnologia estabeleceu o controle na formulação e na manipulação de rações balanceadas, indispensável para se obter resultados produtivos satisfatórios (Seixas-Filho et al., 1999). Contudo, quanto à nutrição de girinos, essas relações encontram-se longe de ter padrões de exigências estabelecidos, que possam ser utilizados pelos nutricionistas.

Para se definir a formulação de rações compatíveis com as exigências nutricionais dos girinos de rã-touro, nas diferentes fases do seu desenvolvimento, é preciso conhecer a fisiologia da digestão desse animal. A eficiência de utilização dos alimentos está diretamente relacionada ao processo digestivo, no qual as enzimas têm papel fundamental (Seixas-Filho et al., 1999).

De modo geral, estudos nutricionais realizados indicam que a rã-touro apresenta melhor desempenho, quando alimentada com dietas com altos valores de proteína bruta, seja na fase de girinos (CarmonaOsalde et al., 1996; Albinati, 2000, 2001; De Stéfani et al., 2001; Hayashi et al., 2004), ou na fase de recria (Braga \& Lima, 2001), sem levar em consideração a sanidade animal.

Barbosa et al. (2005) observaram que níveis protéicos entre 26,6 e $33,6 \%$ são adequados ao desenvolvimento dos girinos, e $22,5 \%$ de proteína bruta causam alta mortalidade.

Estudos realizados por Seixas-Filho et al. (1998a) e Stringuetta et al. (2007) têm buscado uma determinação da ótima relação proteína/energia na dieta para peixes e para rã-touro.

Alguns trabalhos abordam o efeito de certas variáveis sobre o crescimento dos girinos, como o fotoperíodo (Bambozzi et al., 2004), densidade de estocagem (Rodríguez-Serna et al., 1996; Hayashi et al., 2004), temperatura (Braga \& Lima, 2001) e níveis protéicos (Carmona-Osalde et al., 1996; Braga et al., 1998).

Informações a respeito da atividade enzimática em peixes (Moura et al., 2007) e em anfíbios (Braga et al., 2004, 2005, 2006; Oliveira-Bahia, 2007) são escassas na literatura e não existe padronização nos experimentos de bioensaios nutricionais, o que dificulta o seu emprego por nutricionistas.

O objetivo deste trabalho foi avaliar o desempenho e as atividades das enzimas digestivas de girinos de rã-touro alimentados com ração comercial.

\section{Material e Métodos}

O experimento foi conduzido no Laboratório de Pesquisas Biológicas do Centro Universitário Augusto Motta, Rio de Janeiro, RJ, e no Laboratório de Enzimologia, do Instituto de Biotecnologia Aplicada à Agropecuária, da Universidade Federal de Viçosa, Viçosa, MG, de março a abril de 2008.

Foram utilizados 120 girinos de rã-touro, Lithobathes catesbeianus Shaw, 1802 (Frost et al., 2006), no estádio 25 de Gosner (1960), provenientes de uma mesma desova, acondicionados em caixas de polietileno $(62,5 \times 40 \times 16 \mathrm{~cm})$, com capacidade para $40 \mathrm{~L}$, que receberam $30 \mathrm{~L}$ de água e 30 animais (densidade 1 girino por L) com peso e comprimento médio inicial de $0,048 \pm 0,007 \mathrm{~g}$ e $6,52 \pm 0,43 \mathrm{~mm}$, respectivamente.

A renovação da água nas caixas foi de $200 \%$ do volume a cada 24 horas, com abastecimento individual, aeração permanente, e mantida a uma temperatura constante de $25 \pm 1{ }^{\circ} \mathrm{C}$. O nível de água no interior das caixas foi mantido por meio de dispositivo tipo joelho, adaptado na lateral das caixas, onde a água foi escoada por meio de canaletas de PVC acondicionadas lateralmente às bancadas e conectadas ao esgoto.

A ração comercial utilizada na alimentação dos girinos (Tabela 1) foi administrada na granulometria de $0,5 \mathrm{~mm}$, na proporção de $10 \%$ do peso corporal dos girinos por dia e por caixa, fornecida uma vez ao dia, às 12h, conforme Seixas-Filho et al. (1998a, 1998b).

Tabela 1. Níveis de garantias e de composição centesimal da ração comercial empregada na criação de girinos de rã-touro (Lithobathes catesbeianus) $^{(1)}$.

\begin{tabular}{lcc}
\hline Variável & Nível de garantia & Composição analisada \\
\hline Umidade máxima (\%) & 13 & 9,54 \\
Proteína bruta (\%) & 32 & 31,06 \\
Estrato etéreo (mínimo) (\%) & 7 & 5,69 \\
Matéria fibrosa (máximo) (\%) & 7 & \\
Cinzas (máximo) (\%) & 2,6 & 8,85 \\
Cálcio (máximo) (\%) & 12 & \\
Fósforo (mínimo) (\%) & 2 & 4.316 \\
Energia bruta (kcal kg $\left.{ }^{-1}\right)$ & & 38,58 \\
Carboidratos (\%) & & \\
\hline
\end{tabular}

${ }^{(1)}$ Composição básica: farelo de soja, farinha de peixe, farelo de trigo, farelo de glúten de milho $60 \%$, farinha de carne e osso, milho, farinha de sangue, óleo de peixe, carbonato de cálcio, fosfato bicálcico, sal suplemento vitamínico (composição por quilograma: vitamina A, $12.000 \mathrm{UI}$; vitamina D3, 4.000 UI; vitamina E, $150 \mathrm{UI}$; vitamina K, $10 \mathrm{UI}$; ácido fólico, $10 \mathrm{mg}$; biotina, $0,8 \mathrm{mg}$; colina, $500 \mathrm{mg}$; niacina, $150 \mathrm{mg}$; pantotenato de cálcio, $50 \mathrm{mg}$; tiamina, $30 \mathrm{mg}$; riboflavina, $30 \mathrm{mg}$; piridoxina B6, $30 \mathrm{mg}$; vitamina B12, $35 \mu \mathrm{g}$; vitamina C, $300 \mathrm{mg}$ ), sal suplemento mineral (composição por quilograma: Mg, 700 mg; Mn, 30 mg; Zn, 200 mg; Cu, 15 mg; Fe, 100 mg; I, $1 \mathrm{mg}$; Se, 0,3 mg), antioxidante (etoxiquina, $250 \mathrm{mg}$ ). 
Diariamente, foram realizadas: a limpeza das caixas por sifonagem de fundo, retirando-se as fezes e os restos alimentares; o monitoramento das temperaturas do ar e da água; e o monitoramento da amônia e do pH, com auxílio de kit comercial.

O período experimental foi de 60 dias, e as biometrias foram realizadas, quinzenalmente, com quatro exemplares verificando-se a taxa de sobrevivência, o peso final, o comprimento e as mudanças morfológicas dos estágios larvais, segundo Gosner (1960).

Para avaliação do consumo, a sobra da ração foi retirada dos cochos a cada 24 horas, por sifonagem, sem contaminação com as fezes. As sobras foram secadas em estufa ventilada a $55^{\circ} \mathrm{C}$, durante 72 horas. $\mathrm{O}$ consumo foi obtido pela diferença entre a quantidade oferecida e a sobra de ração.

A conversão alimentar aparente foi obtida pela razão entre o consumo de ração e o ganho de peso. A taxa de crescimento específico foi calculada pela expressão: $\mathrm{TCE}=[(\log$ natural do peso final $-\log$ natural do peso inicial)x100]/período experimental (dias).

Para as análises das atividades das enzimas digestivas nos quimos dos girinos, foram coletados, quinzenalmente, quatro exemplares. Os animais foram imersos em banho de gelo a $-4^{\circ} \mathrm{C}$ e anestesiados com mentol a $1 \%$ adicionado à água; em seguida, foram contidos fisiologicamente e submetidos à necropsia, em cama de gelo, para retirada do intestino.

Os animais sofreram incisão longitudinal ventral, e o isolamento do tubo digestório foi realizado após ligaduras duplas na porção cranial do esôfago e na porção caudal do reto, anteriormente ao ânus, para que não houvesse extravasamento do quimo. Em seguida, foi retirado o intestino da cavidade peritoneal $\mathrm{e}$ isolado dos outros órgãos, do final do manicoto até a extremidade distal, e acondicionado em frascos de polietileno, e imediatamente armazenado em freezer a $-8^{\circ} \mathrm{C}$, até o procedimento das análises de atividade enzimática.

Para as análises de amilase, lipase e tripsina foi utilizado $0,5 \mathrm{~g}$ de cada amostra congelada e 1,5 mL de tampão (Tris-HCl 0,1M), para descongelamento e maceração. Em seguida, esse material foi centrifugado a $15.000 \mathrm{rpm}$ por $15 \mathrm{~min}$, a $4^{\circ} \mathrm{C}$, e o sobrenadante foi utilizado para as determinações das atividades, em duplicata.

A determinação da atividade de amilase foi realizada utilizando-se o kit de amilase colorimétrica da Bioclin, segundo Caraway (1959). As atividades de lipase foram determinadas utilizando-se o kit Bioclin, segundo método de Cherry \& Crandall (1932) modificado. As atividades de tripsina foram determinadas pelo método de Erlanger et al. (1961), utilizando-se N-benzoil-D, L-arginina p-nitroanilida (D, L-BApNA) como substrato.

A concentração de proteína, para todas as amostras das diferentes enzimas, foi medida na absorvância de $280 \mathrm{~nm}$ e os ácidos nucléicos a $260 \mathrm{~nm}$, segundo Warburg \& Christian (1941).

Os dados foram submetidos à análise de regressão. Foram testados modelos lineares de cada parâmetro em função do período de experimentação, e a escolha da melhor equação deu-se pelo maior coeficiente de determinação $\left(\mathrm{R}^{2}\right)$, pela significância dos coeficientes de regressão por meio do teste $\mathrm{t}$, a 5 e $1 \%$ de probabilidade e por sua adequação biológica.

\section{Resultados e Discussão}

A temperatura do ar local apresentou médias mínimas e máximas de 25 e $30^{\circ} \mathrm{C}$, respectivamente. A temperatura média da água observada foi de $25 \pm 1{ }^{\circ} \mathrm{C}$. $\mathrm{O}$ pH manteve-se na faixa de 7,5 $\pm 0,5$ e a amônia total foi de 0 a 0,25 ppm, e manteve-se dentro do desejado, sendo semelhantes aos das condições do trabalho de Tavares (1994).

Foi observada redução significativa $(\mathrm{P}<0,05)$ na sobrevivência dos animais entre o $15^{\circ}(97,78 \%)$ e o $60^{\circ}$ dia $(80,00 \%)$ de experimentação. Estes resultados foram semelhantes aos $82 \%$ de sobrevivência relatados por Seixas-Filho et al. (1998b) em girinos arraçoados com $32 \%$ de proteína bruta e $4.200 \mathrm{kcal} \mathrm{kg}^{-1}$ de energia bruta. Por outro lado, foram inferiores aos $97 \%$ de sobrevivência obtida por Albinati et al. (2001) nos girinos alimentados com ração com 35,61\% de proteína bruta e $3.954 \mathrm{kcal} \mathrm{g}^{-1}$ de energia digestível. Entretanto, De Stefani et al. (2001) e Barbosa et al. (2005) relataram sobrevivência de 60 e $50 \%$, quando utilizaram rações experimentais com $35,03 \%$ de proteína bruta e $4.174 \mathrm{kcal} \mathrm{kg}^{-1}$ de energia bruta e rações isocalóricas de 22,5 a $33,6 \%$ de proteína bruta e $4.100 \mathrm{kcal} \mathrm{kg}^{-1}$ de energia bruta, respectivamente.

Para o peso final e o comprimento, foi observado efeito quadrático $(\mathrm{p}<0,01)$ ao longo do período experimental (Figura 1). Houve maior crescimento dos girinos entre o $15^{\circ}$ e o $45^{\circ}$ dia $(20,61 \mathrm{~mm})$, sendo o 
menor crescimento $(2,47 \mathrm{~mm})$ observado no final do experimento. Nos primeiros 15 dias e considerando a adaptação fisiológica à ração, os animais apresentaram o menor ganho de peso, de 0,542 g, em relação aos outros períodos. Porém, foi observada maior taxa de crescimento específico, de $16,73 \%$ por dia, o que pode estar associada a um metabolismo mais acentuado dessa espécie nessa mesma fase.

A redução do crescimento observada do $45^{\circ}$ ao $60^{\circ}$ dia de experimento pode estar relacionada à fase
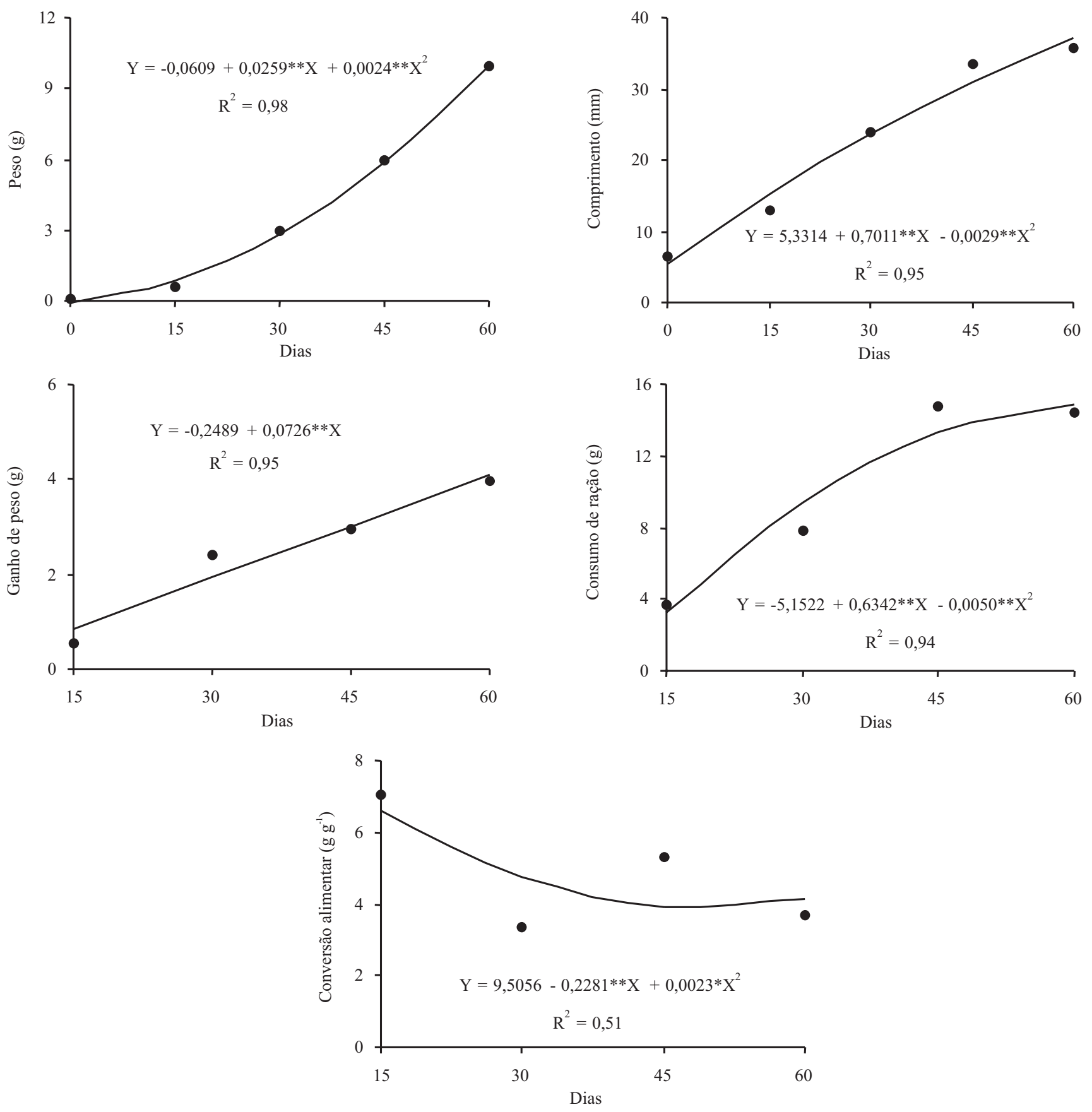

Figura 1. Peso, comprimento, ganho de peso, consumo de ração e conversão alimentar de girinos de rã-touro, alimentados com ração comercial com $32 \%$ de proteína bruta, durante 60 dias. * e**Significativo a 5 e $1 \%$ de probabilidade, respectivamente. 
pré-metamórfica, na qual os animais exteriorizam seus membros posteriores. Porém, durante essa fase, foi observado maior ganho de peso, de 3,958 g, em conseqüência da melhora no consumo, de 14,405 g, e da conversão alimentar (3,67:1). Também foi verificado melhora no desempenho de girinos de 15 a 30 dias, o que pode estar relacionada com o desenvolvimento do sistema digestório, aumentando o aproveitamento dos nutrientes da dieta.

Stringuetta et al. (2007) estudando girinos, na densidade de 2,5 girinos por litro, obtiveram menor ganho de peso $(0,45 \mathrm{~g})$, porém com melhor conversão alimentar (2,18:1), quando comparados com os resultados deste trabalho. Por outro lado, Barbosa et al. (2005) alcançaram menor desempenho dos girinos alimentados com rações com diferentes níveis de proteína bruta.

A atividade de amilase, lipase e tripsina foram verificadas desde o primeiro dia de coleta do quimo dos girinos. Esses resultados sugerem que os girinos têm capacidade de utilizar os carboidratos, lipídeos e proteínas de dietas artificiais.

Para a atividade específica da amilase, foi verificado efeito linear $(p<0,05)$ em relação às fases de desenvolvimento (Figura 2). Observou-se que, aos 15 dias do experimento - quando os girinos apresentavam-se no 26ํㅜ estágio larval (Gosner, 1960), fase pré-metamórfica - a atividade específica já alcançava 55,36 $\mathrm{UA} \mathrm{mg}^{-1}$. Passou a $62,57 \mathrm{UA} \mathrm{mg}^{-1}$ no $30^{\circ}$ dia - quando os animais encontravam-se do $30^{\circ}$ ao $32^{\circ}$ estágio larval, final da fase pré-metamórfica e início da fase pró-metamórfica (Gosner, 1960) - e aumentou no $45^{\circ}$ dia para $69,78 \mathrm{UA} \mathrm{mg}^{-1}$, com os girinos do $34^{\circ} \mathrm{e}$ 35o estágio larval, na metade da fase pró-metamórfica (Gosner, 1960). Aumentou ainda mais no 60 dia (76,99 UA $\left.\mathrm{mg}^{-1}\right)$, chegando ao final da fase pró-metamórfica (Gosner, 1960), estando os girinos no $38^{\circ}$ estágio larval. Com isso, ao final do experimento, houve um aumento de, aproximadamente, 151 vezes na capacidade de hidrólise de amido, quando comparada à sua capacidade inicial $\left(0,51 \mathrm{UA} \mathrm{mg}^{-1}\right)$. Esses resultados concordam com os de Leone et al. (1976) que, ao analisar o perfil da atividade enzimática da amilase e lipase dos girinos de Xenopus laevis, observaram que essas enzimas possuíam um pico de atividade entre os estágios $29^{\circ}$ e $38^{\circ}$, os quais correspondiam ao maior nível de organização ultraestrutural das células acinares, correspondendo, neste trabalho, do $30^{\circ}$ ao $60^{\circ}$ dia.
O aumento da capacidade hidrolítica da amilase, observado no $60^{\circ}$ dia, está de acordo com Etkin (1968), que afirmou que do $36^{\circ}$ ao $40^{\circ}$ estágio (fase pró-metamorfose) ocorre o maior crescimento corpóreo dos girinos, o que leva a maior consumo de nutrientes e, conseqüentemente, à necessidade de um aporte maior de enzimas. Resultados semelhantes foram obtidos por Oliveira-Bahia (2007), que relatou elevado aumento na atividade de amilase do $36^{\circ}$ ao $40^{\circ}$ estágio, no fígado e pâncreas de girinos de $L$. catesbeianus, o que correspondeu neste trabalho, à última quinzena experimental.

Houve efeito quadrático $(\mathrm{p}<0,05)$ para atividade específica de lipase. Nos primeiros 15 dias, a maior atividade específica de lipase nos girinos (31,50 UI) pode ser explicada pelo fato de os anfíbios terem alto metabolismo nesta fase, o que requer maiores níveis de energia para sustentar o seu desenvolvimento. Dos 45 aos 60 dias do experimento, com a chegada da fase pré-metamórfica, ocorreu aumento na atividade específica de lipase. Provavelmente, isto ocorreu pela melhor funcionalidade do pâncreas, e pelo requerimento maior de energia para o desenvolvimento dos membros posteriores nesta idade, concordando com Oliveira-Bahia (2007).

A atividade específica da tripsina, no início do experimento, apresentou baixa capacidade para hidrólise do substrato $\left(0,19 \mathrm{nM} \mathrm{s}^{-1} \mathrm{mg}^{-1}\right)$. Aos 15 dias de experimentação ocorreu aumento na sua capacidade de hidrólise, da ordem de 2,3 vezes $\left(0,43 \mathrm{nM} \mathrm{s}^{-1} \mathrm{mg}^{-1}\right)$, quando comparado à inicial. No $30^{\circ}$ dia, houve discreto aumento de 5,95 vezes $\left(1,13 \mathrm{nM} \mathrm{s}^{-1} \mathrm{mg}^{-1}\right)$, em relação à capacidade inicial e, de 2,3 vezes, se comparado com a quinzena anterior. Entretanto, a partir do 45을 dia aumentou 17 vezes $\left(3,26 \mathrm{nM} \mathrm{s}^{-1} \mathrm{mg}^{-1}\right)$ sua capacidade hidrolítica, em relação à capacidade inicial $\left(0,19 \mathrm{nM} \mathrm{s}^{-1} \mathrm{mg}^{-1}\right) \mathrm{e}$, de 2,9 vezes, quando comparada à quinzena anterior. Ao final do período experimental, a atividade específica de tripsina foi de $6,84 \mathrm{nM} \mathrm{s}^{-1} \mathrm{mg}^{-1}$, correspondendo a 36 vezes à capacidade inicial de hidrólise e a 2,10 vezes maior que o período anterior analisado.

Estes resultados demonstram que, para as três enzimas, ocorreu aumento significativo da capacidade de ação sobre o quimo dos girinos após o $30^{\circ}$ dia de experimentação. Isto corrobora os dados de Leone et al. (1976), que relatam, para girinos de X. laevis, que somente a partir do estágio 29 (Gosner, 1960) 
ocorreu o completo amadurecimento das estruturas responsáveis pela síntese e secreção das enzimas. Esse esstágio corresponde neste trabalho ao período do $15^{\circ}$ ao $30^{\circ}$ dia, após o início da alimentação exógena.

Estes resultados sugerem, ainda, que a atividade específica da amilase aumenta exponencialmente nos
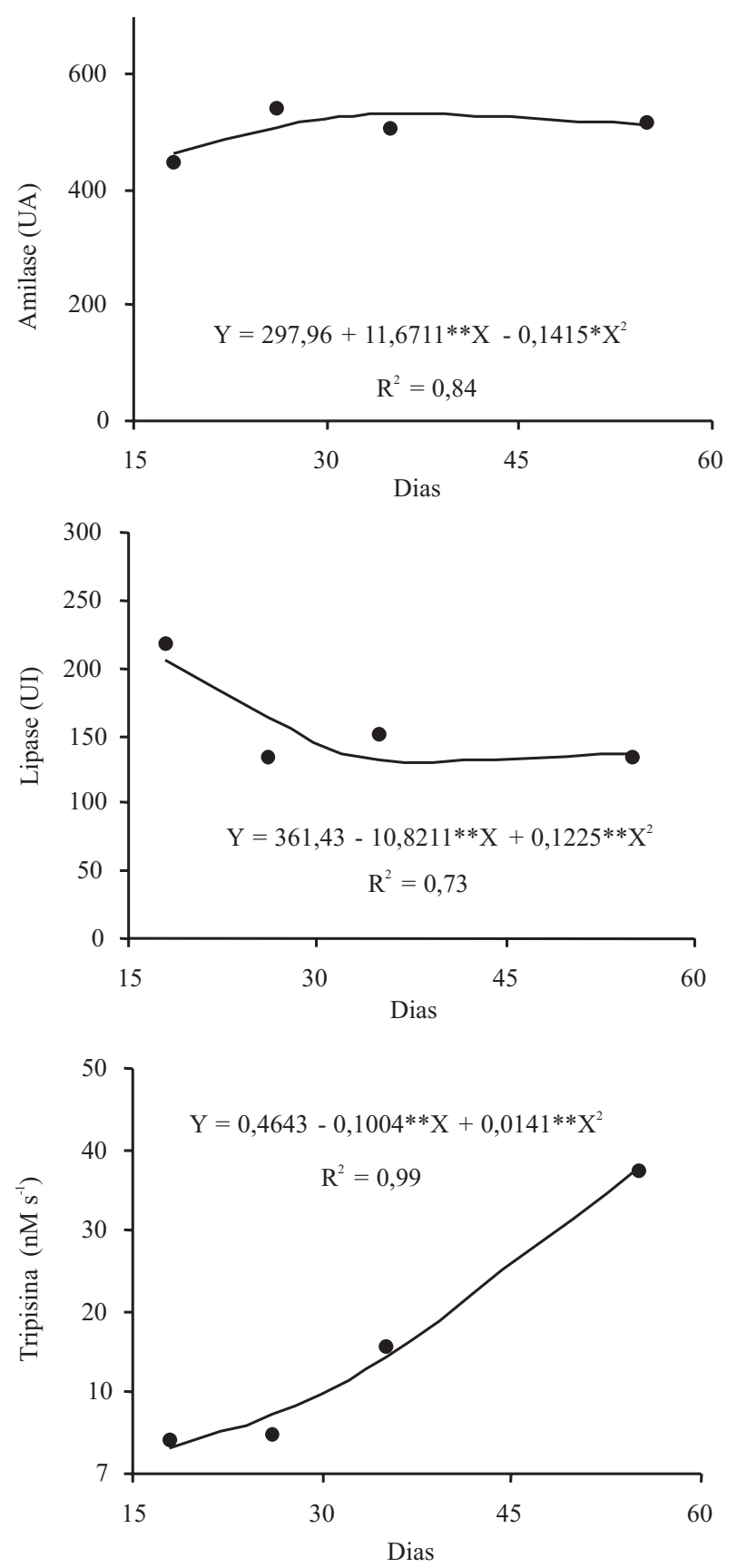

primeiros 15 dias do experimento e sustenta crescimento diretamente proporcional do $15^{\circ}$ ao $60^{\circ}$ dia. Já a atividade específica da lipase repete o comportamento inicial da atividade específica da amilase, porém, após o $15^{\circ}$ dia decresce sugerindo que as gorduras ingeridas foram estocadas na cauda ao invés de serem
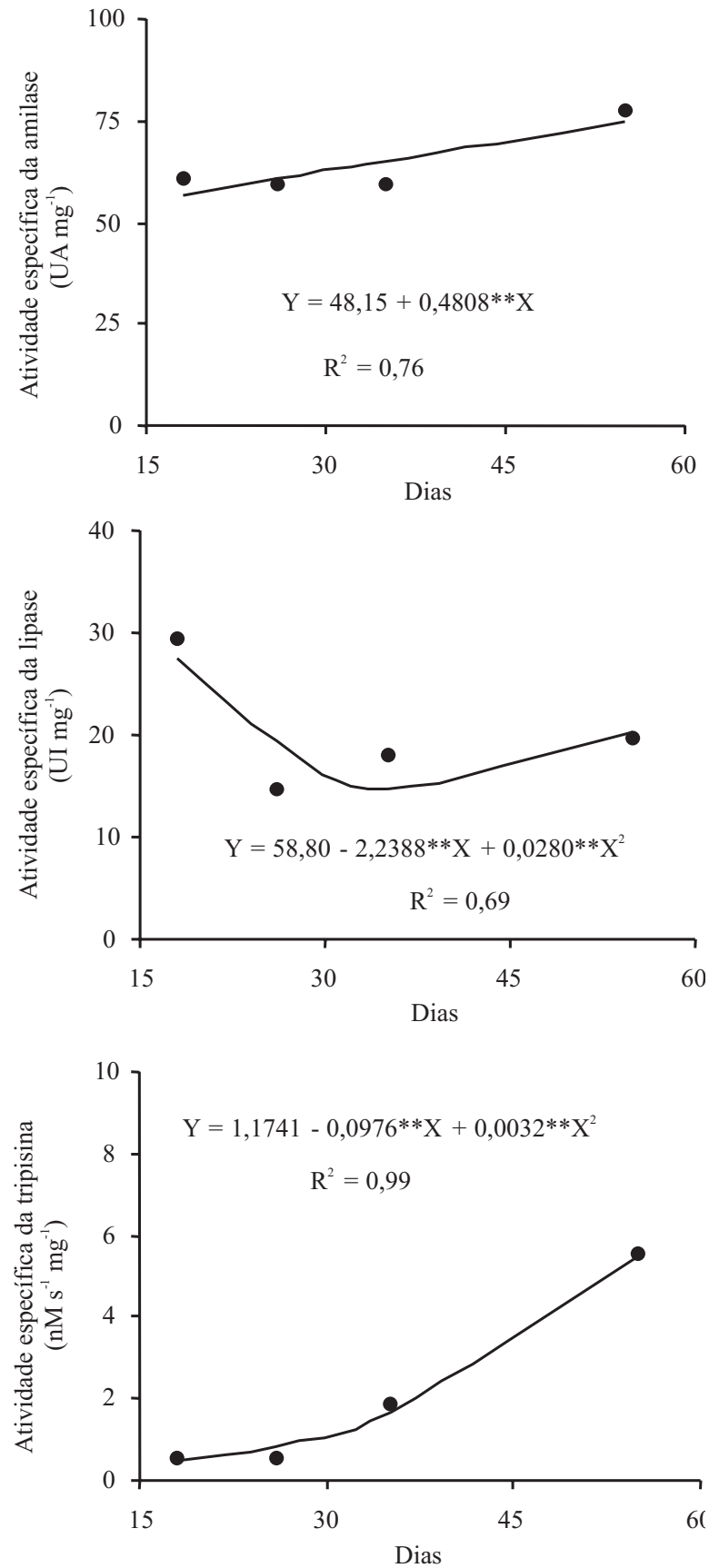

Figura 2. Atividade enzimática da amilase, lipase e tripsina e atividade específica da amilase, lipase e tripsina no quimo de girinos da rã-touro, alimentadas com ração comercial com $32 \%$ de proteína bruta. ${ }^{*}{ }^{* *}$ Significativo a 5 e $1 \%$ de probabilidade, respectivamente. 
usadas na construção do organismo; a partir do 45ำ dia experimental, início da pré-metamorfose, ocorreu aumento da atividade específica da lipase, aparentemente responsável pela mobilização das reservas constituídas na cauda dos girinos. A atividade específica da tripsina apresentou crescimento diretamente proporcional ao do peso corporal, o que indica relação direta com o desenvolvimento do organismo animal.

O melhor desempenho dos animais, apresentado na última quinzena do experimento, está diretamente relacionado à maior capacidade hidrolítica das enzimas. Isto refletiu no aumento do ganho de peso com a melhor conversão alimentar $(3,67: 1)$, e acarretou peso final dos girinos de 9,936 g. Este peso final é considerado bom para os animais que ainda estão iniciando a fase pré-metamórfica, indicando a formação de imagos dentro dos padrões dos ranários comerciais, com menor custo operacional na alimentação.

Contudo, durante a necropsia, quando da retirada do quimo para as análises enzimáticas, observou-se que os fígados apresentavam modificações na sua coloração e constituição, totalmente embranquecidas (cor palha e manchado) e com perda da consistência normal, não chegando estar friáveis. Tais lesões sugerem um quadro degenerativo nutricional, com desenvolvimento de processos inflamatórios associados à deficiência protéica, conforme relatado por Hipólito et al. (2004, 2007), podendo-se inferir que ocorreu um quadro de toxidez metabólica, por acúmulo de nitrogênio oriundo de aminoácidos não metabolizados, de acordo com Leone et al. (1976) e Boorman (1980) ou, ainda, sugerem que os animais foram alimentados com proteínas de pouco valor biológico, indicando, aparentemente, má qualidade das rações, o que comprometeu sua sanidade $\mathrm{e}$, conseqüentemente, o seu desempenho.

Portanto, o conhecimento das alterações morfofisiológicas é de fundamental importância para o entendimento dos mecanismos inerentes à digestão de nutrientes, em cada fase do desenvolvimento dos girinos, e assim, fornecer embasamento à nutrição e ao manejo desses animais em cativeiro.

\section{Conclusão}

Ocorre aumento das atividades específicas das três enzimas no quimo dos girinos após o $30^{\circ}$ dia, o que reflete na melhoria do desempenho dos animais até o $60^{\circ}$ dia.

\section{Referências}

ALBINATI, R.C.B.; LIMA, S.L.; DONZELE, J.L. Níveis de energia digestível na ração de girinos de rã-touro. Revista Brasileira de Saúde da Produção Animal, v.2, p.48-52, 2001.

ALBINATI, R.C.B.; LIMA, S.L.; TAFURI, M.L.; DONZELE, J.L. Digestibilidade aparente de dois alimentos protéicos e três energéticos para girinos de rã-touro (Rana catesbeiana Shaw, 1802). Revista Brasileira de Zootecnia, v.29, p.2151-2156, 2000.

BAMBOZZI, A.C.; SEIXAS-FILHO, J.T. de; THOMAZ, L.A.; OSHIRO, L.M.Y.; BRAGA, L.G.T.; LIMA, S.L. Efeito do fotoperíodo sobre o desenvolvimento de girinos de rã-touro (Rana catesbeiana Shaw, 1802). Revista Brasileira de Zootecnia, v.1, p.1-7, 2004.

BARBOSA, J.M.; SILVEIRA, A.M.; GOMIDE, C.A. Crescimento heterogêneo de girinos de rã-touro alimentados com diferentes rações. Pesquisa Agropecuária Brasileira, v.40, p.1015-1019, 2005.

BOORMAN, K.N. Dietary constraints on nitrogen retention. In: BUTTERY, P.J.; LINSANY, D.B. Protein deposition in animals. London: Butterworths, p.147-166, 1980.

BRAGA, L.G.T.; LIMA, S.L. Influência da temperatura no desempenho da rã-touro, Rana catesbeiana (Shaw, 1802) na fase de recria. Revista Brasileira de Zootecnia, v.30, p.1659-1663, 2001.

BRAGA, L.G.T.; LIMA, S.L.; DONZELE, J.L.; CASTRO, J.C. Valor nutritivo de alguns alimentos para rã-touro (Rana catesbeiana Shaw, 1802) na fase de recria. Revista Brasileira de Zootecnia, v.27, p.203-209, 1998.

BRAGA, L.G.T.; OLIVEIRA, M.G. de A.; LIMA, W.C.; EUCLYDES, R.F. Atividade da amilase em rã-touro durante a fase pós-metamórfica. Pesquisa Agropecuária Brasileira, v.40, p.947-951, 2005.

BRAGA, L.G.T.; OLIVEIRA, M.G. de A.; LIMA, W.C.; EUCLYDES, R.F. Atividade da tripsina em rã-touro na fase pós-metamórfica. Revista Brasileira de Zootecnia, v.33, p.821-827, 2004.

BRAGA, L.G.T.; OLIVEIRA, M.G. de A.; LIMA, W.C.; EUCLYDES, R.F. Enzymatic activity of lipase in postmetamorphic phase bullfrogs. Scientia Agricola, v.63, p.439-443, 2006.

CARAWAY, W.T. A stable starch substrate for the determination of amylase in serum and other body fluids. American Journal of Clinical Pathology, v.32, p.97-99, 1959.

CARMONA-OSALDE, C.; OLVERA-NOVOA, M.A.; RODRÍGUEZ-SERNA, M.; FLORES-NAVA, A. Estimation of the protein requirement for bullfrog (Rana catesbeiana) tadpoles, and its effect on metamorphosis ratio. Aquaculture, v.141, p.223-231, 1996.

CHERRY, I.S.; CRANDALL JUNIOR, L.A. The specificity of pancreatic lipase: its appearance in the blood after pancreatic injury. American Journal of Physiology, v.100, p.266-273, 1932.

De STÉFANI, M.V.; MARCANTONIO, A.S.; MARTINS, M.L. Suplementação com vitamina $\mathrm{C}$ e E sobre o desenvolvimento e sobrevivência de girinos de rã-touro (Rana catesbeiana Shaw, 1802). Ciência Rural, v.31, p.869-871, 2001. 
ERLANGER, B.F.; KOKOWSKY, N.; COHEN, N. The preparation and properties of two new chromogenic substrates of trypsin. Archives of Biochemistry and Biophysics, v.95, p.271-278. 1961.

ETKIN, W. Hormonal control of amphibian metamorphosis. In: ETKIN, W.; GILBERT, L.I. (Ed.). Metamorphosis: a problem in developmental biology. New York: Appleton, 1968. p.313-348.

FROST, D.R.; GRANT, T.; FAIVOVICH, J.; BAIN, R.H.; HAAS, A.; HADDAD, C.F.B.; SÁ, R.O. de; CHANNING, A.; WILKINSON, M.; DONNELLAN, S.C.; RAXWORTHY, C.J.; CAMPBELL, J.A.; BLOTTO, B.L.; MOLER, P.; DREWES, R.C.; NUSSBAUM, R.A.; LYNCH, J.D.; GREEN, D.M.; WHEELER, W.C. The amphibian tree of life. New York: American Museum of Natural History, 2006. 370p. (Bulletin of the American Museum of Natural History, 297).

GOSNER, K.L. A simplified table for staging anuran embryos and larvae with notes on identification. Herpetologica, v.16, p.183-190, 1960.

HAYASHI, C.; SOARES, C.M.; GALDIOLI, E.M.; FURUYA, V.R.B.; BOSCOLO, W.R. Desenvolvimento de girinos de rã-touro (Rana catesbeiana Shaw, 1802) cultivados em diferentes densidades de estocagem em tanques-rede. Revista Brasileira de Zootecnia, v.33, p.14-20, 2004.

HIPOLITO, M.; MARTINS, A.M.C.R.P.F.; BACH, E.E. Aspectos bioquímicos em fígado de rãs-touro (Rana catesbeiana Shaw, 1802) sadias e doentes. Arquivos do Instituto Biológico, v.71, p.147-153, 2004.

HIPÓLITO, M.; RIBEIRO FILHO, O.P.; BACH, E.E. Aspecto bioquímico em fígados de Rana catesbeiana (Shaw, 1802) submetida a diferentes dietas. ConScientiae Saúde, v.6, p.49-56, 2007.

LEONE, F.; LAMBERT-GARDINI, S.; SARTORI, C.; SCARPIN, S. Ultrastructural analysis of some functional aspects of Xenopus laevis pancreas during development and metamorphosis. Journal of Embryology and Experimental Morphology, v.36, p.711-724, 1976.

LIMA, S.L.; AGOSTINHO, C.A. A tecnologia de criação de rãs. Viçosa: UFV, 1992. 168p.
MOURA, G.de S.; OLIVEIRA, M.G.A.;LANNA, E.T.A.; MACIEL JÚNIOR, A.; MACIEL, C.M.R.R. Desempenho e atividade de amilase em tilápias-do-nilo submetidas a diferentes temperaturas. Pesquisa Agropecuária Brasileira, v.42, p.1609-1615, 2007.

OLIVEIRA-BAHIA, V.R.L. Morfologia e enzimologia do sistema digestório dos girinos da rã-touro (Rana catesbeiana) durante o desenvolvimento e metamorfose. 148p. 2007. Tese (Doutorado) Universidade Estadual Paulista, Jaboticabal.

RODRÍGUEZ-SERNA, M.; FLORES-NAVA, A.; OLIVERANOVOA, M.A.; CARMONA-OSALDE, C. Growth and production of bullfrog Rana catesbeina Shaw, 1802, at three stocking densities in a vertical intensive culture system. Aquacultural Engineering, v.15, p.233-242, 1996.

SEIXAS-FILHO, J.T.; MELLO, S.C.R.P.; SILVA, J.M.F.; TOMAS, J.E.; MELO, C.M.S. Efeito dos níveis de energia e proteína bruta no desempenho de girinos (Rana catesbeiana Shaw, 1802). Revista Brasileira de Zootecnia, v.27, p.664-669, 1998a.

SEIXAS-FILHO, J.T.; MELLO, S.C.R.P.; VEIGA, R.C.A.; MIRANDA, R.G.B.; SANTOS, C.A.N. Efeito da granulometria da ração sobre o desempenho de girinos de Rana catesbeiana. Revista Brasileira de Zootecnia, v.27, p.224-230, 1998 b.

SEIXAS-FILHO, J.T.; OLIVEIRA, M.G. de A.; DONZELE, J.L.; GOMIDE, A.T.M.; MENIN, E. Avaliação da atividade de amilase em quimo de três espécies tropicais de peixes Teleostei. Revista Brasileira de Zootecnia, v.28, p.907-913, 1999.

STRINGUETTA, L.L.; BOSCOLO, W.R.; FEIDEN, A.; SOUZA, B.E. de; MANSKE, C.; OLIVEIRA, C.L. de. Inclusão de farinha de resíduos da indústria de filetagem de tilápias na alimentação de girinos de rã-touro (Rana catesbeiana Shaw, 1802). Semina: Ciências Agrárias, v.28, p.747-752, 2007.

TAVARES, L.H.S. Limnologia aplicada à aqüicultura. Jaboticabal: Funep, 1994. 70p.

WARBURG, O.; CHRISTIN, W. Isohering und kristallisation dês görungs ferments enolase. Biochemistry Zoology, v.310, p.384-421, 1941.

\footnotetext{
Recebido em 20 de junho de 2008 e aprovado em 13 de outubro de 2008
} 